\title{
La irrupción del estribo en la caballería romana de la antigüe- dad tardía y su aplicación táctica durante el reinado del empera- dor Heraclio (610-641 d.C.). Una aproximación historiográfica \\ The irruption of the stirrup in the Roman cavalry of late antiquity and its tactical application during the reign of the Emperor Heraclius (610-641 AD). An historiographical approach
}

\section{Luis Alfredo De la Peña*}

\section{Resumen}

La innovación táctica ha sido uno de los motores fundamentales del cambio y desarrollo de la guerra como actividad a lo largo de la historia. Estos cambios han sellado el destino de imperios y naciones enteras, así como han significado la diferencia entre la vida y la muerte para miles de combatientes. El objetivo de este artículo es analizar, a través de la historiografía, la importancia táctica del uso del estribo para las fuerzas a caballo del Imperio romano de oriente y cómo la apropiación y aplicación de este elemento estableció una ventaja táctica contra sus contendientes por la dominación del medio oriente durante el siglo VII d.C. Esto sin dejar atrás la importancia que el estribo ha tenido desde su masificación durante las guerras entre romanos y sasánidas hasta nuestro contexto, en donde se libraron guerras y se independizaron países luchando a caballo con o sin estribos.

Palabras clave: Innovación Táctica, Historia Militar, Antigüedad Tardía, Imperio Bizantino, Caballería, Estribos.

\section{Abstract}

Tactical innovation has been one of the fundamental engines of war change and development as an activity throughout history. These changes have sealed the fate of empires and entire nations, as well as have made the difference between life and death for thousands of combatants. The objective of this article is to analyze, through historiography, the tactical importance of the use of the stirrup for the forces on horseback of the Eastern Roman Empire, and how the appropriation and application of this element established a tactical advantage against its contenders for the domination of the Middle East during the century VII A. D. Without leaving behind the importance that the stirrup has had from its massification during the wars between Romans and Sassanids to our context, where wars were fought and countries became independent fighting on horseback with or without stirrups.

Keywords: Tactical Innovation, Military History, Late Antiquity, Byzantine Empire, Cavalry, Stirrup

\footnotetext{
* Historiador de la Universidad Nacional de Colombia sede Bogotá. Máster en Historia Militar de las guerras contemporáneas de la Universidad Jaume I en Castellón, España; Máster en Historia Comparada de la Central. European University en Budapest, Hungría. Correo electrónico: luisdelapej@gmail.com
} 
Para citar el artículo: De la Peña, Luis. "La irrupción del estribo en la caballería romana de la antigüedad tardía y su aplicación táctica durante el reinado del emperador Heraclio (610641 d.C.). Una aproximación historiográfica”. Revista Artificios, n. 17 (2020): 31-46.

Fecha de recepción: 25 de mayo de 2020

Fecha de aceptación: 12 de agosto de 2020 
"[...]Montan a caballo perfectamente y, hasta cuando van a galope tendido, son capaces de tensar sin dificultad sus arcos hacia uno y otro lado y dispararles a los enemigos tanto en una persecución como en una huida. Tiran de la cuerda y la traen a lo largo de la frente, justo hasta la oreja derecha, con lo que le dan a la flecha tanta fuerza que matan a quien entonces se ponga delante, sin que ni siquiera un escudo ni una coraza sirva de algo para contrarrestar el impulso. Hay también quienes, no teniendo en cuenta nada de todo esto, rinden culto y admiración a los tiempos antiguos y no les dan importancia a los adelantos que se inventan.» ${ }^{l}$

Es por lo menos curioso escribir un ensayo sobre espacios y periodos ajenos a los que tradicionalmente se han estudiado en la historiografía nacional, una curiosidad que se vuelve aún más arcana si este análisis trata sobre los convulsionados siglos entre la transición de la antigüedad clásica a la edad media. Aun así, el estudio del Imperio romano de Oriente no es ajeno a la actividad intelectual en nuestro país, ni mucho menos ajeno a la historiografía que cuenta con un estimulante estudio escrito por Álvaro Uribe Rueda, quien conecta la caída de Constantinopla (y con ella, la de los últimos vestigios de la continuación de la civilización romana clásica) ante las fuerzas otomanas el 29 de mayo de 1453, con la llegada de los europeos al continente americano en $1492^{2}$. Conectando, a través de las dos fechas tradicionales del paso del medioevo a la modernidad, la historia de Bizancio con nuestra historia que, mediante ese contacto, pasaba a ser parte de una historia compartida y global.

Del mismo modo, es común encontrar referencias en la historiografía militar sobre cómo ciertos instrumentos de guerra (en la mayoría de los casos, armas), técnicas y desarrollos científicos, o ideas y nuevas estrategias han cambiado la forma de enfrentar a los ejércitos y, de la misma manera, dar un nuevo curso de los acontecimientos a lo largo de la historia. El mantenimiento de fuerzas armadas, el adoctrinamiento de hombres (y en ciertos casos mujeres y niños) dispuestos a morir o matar, y la escogencia de la forma y los elementos con los que se libra una batalla son elementos decisivos en el resultado de un encuentro bélico y podrían borrar la delgada línea entre la vida y la muerte o la victoria y la derrota. Por esta razón, el uso exitoso del mejor o más innovador equipo era de vital importancia para los comandantes de las tropas y sus subordinados. La cuestión entonces re-

1 Procopio de Cesarea, Historia de las guerras. Obra completa. Volumen I: Guerra Persa. Libros I-II. Traducción del griego de Francisco Antonio García Romero (Madrid: Editorial Gredos, 2000): 14-16.

2 Álvaro Uribe Rueda, Bizancio, el dique iluminado: la concepción mística del universalismo, sus raíces judias y helénicas y su herencia cristiana (Bogotá: Instituto Caro y Cuervo, 1997): 614. 
caería en cómo adquirir, desarrollar y aplicar esa nueva ventaja táctica en los campos de batalla.

Adrián David Bivar sugiere tres elementos que, en determinado momento, significaron un punto de inflexión táctico y transformaron la historia de la guerra convirtiéndose en un equipo fundamental de la guerra medieval. Estos elementos son la cota de malla, el arco compuesto y el estribo ${ }^{3}$. Es sobre esto último, ubicado temporal y geográficamente, el análisis de este trabajo en la antigüedad tardía, puntualmente en el establecimiento militar del Imperio romano de Oriente. El objetivo de este trabajo será analizar las fuentes primarias, especialmente el Strategikon de Mauricio y la historiografía escrita sobre el tema, para analizar el estribo como elemento revolucionario de la indumentaria de caballería, su apropiación y uso durante el reinado del emperador Heraclio (quien reinó del año 610 al 641 de nuestra era) y resaltar su importancia posterior en el desarrollo de las guerras y conflictos durante los siguientes siglos, en el espacio Euroasiático.

Pero antes de entrar completamente en materia, es importante hacer una digresión sobre los términos utilizados para referirse al imperio emplazado en la mitad oriental del mar Mediterráneo durante la antigüedad tardía. Roma, Bizancio, Imperio Romano de Oriente, las denominaciones son varias y el debate sobre cuál debería prevalecer es inmenso y aún está en marcha. Aun así, es menester recalcar que el término "Bizancio" fue acuñado por primera vez por Hieronymus Wolf, un intelectual bávaro, quien en su obra Corpus Historiae Byzantinae (Cuerpo de historia bizantina) fue el primero en repensar la historiografía del Imperio romano, para diferenciar, por razones académicas, a la mitad occidental del imperio con capital en Roma y prevalencia durante la antigüedad y de habla latina, de la mitad oriental con protagonismo durante el medioevo y de habla griega ${ }^{4}$.

Es así como, desde hace cuatro siglos, la historiografía occidental ha reemplazado gradualmente el término "romano" por el de "bizantino", a pesar de que, ni antes ni después de la caída de Constantinopla, sus habitantes o sus herederos se denominaran a sí mismos como "bizantinos". Es por esta razón que en este artículo y por cuestiones que responden al estilo y ritmo del texto, se usan indistintamente ambos términos al ser ambos, por la anterior explicación, correctos. Pese a que historiadores, profesionales o no, aún consideren que entre los emperadores bizantinos y los césares romanos no exista ninguna relación ${ }^{5}$. Luego de esta aclaración, es momento de volver al tema

3 A. D. H. Bivar, "Cavalry Equipment and Tactics on the Euphrates Frontier", Dumbarton Oaks Papers 26 (1972): 276, www.jstor.org/stable/1291323

4 La titánica obra de Wolf está digitalizada y se puede consultar completamente, véase: Hieronymus Wolf, Corpus Historiae Byzantinae. (Fráncfort, 1568), http://mdz-nbn-resolving.de/urn:nbn:de:bvb:12bsb10140060-5

5 Para aclaraciones sobre el uso y categorización de los terminos "romano" bizantino" "romano oriental" "ortodoxo" "constantinopolita" entre otros, véase Jeffreys, Elizabeth, John F. Haldon y Robin Cormack, eds. The Oxford Handbook of Byzantine Studies (Oxford: Oxford Handbooks, 2008), 4. 
central de este artículo: la irrupción y adaptación del estribo en la caballería del Imperio romano de Oriente durante el reinado del emperador Heraclio.

\section{El estribo como una mejora táctica trascendental}

El estribo podría haber surgido en el subcontinente indio, pero en el siglo V los chinos lo adoptaron para luego hacerlo los pueblos de la estepa, desde donde pasó rápidamente a Europa. Su importancia es objeto de una feroz controversia entre quienes afirman que al darle al jinete un asiento firme, éste se transformó en un lancero de infantería montado y los escépticos que refutan que el jinete nómada sin estribos no se identificaba de la mejor manera con su montura. Como la evidencia documental y arqueológica disponible no confirma ninguna de las dos tesis, no es una discusión en la que se deba entrar en este artículo. Pero se sabe que desde el siglo VIII, en Occidente, el guerrero a caballo montaba con una silla alta, mantenía los pies en los estribos $\mathrm{y}$, en consecuencia, podía manejar armas y tener equipos previamente circunscritos al soldado de infantería. Es cierto que los persas sasánidas y, más tarde los bizantinos, habían dispuesto en orden de combate escuadrones de caballería blindada e incluso caballos con armadura mucho antes, pero no sabemos cómo estaban equipados o cómo lucharon y es, a todas luces, engorroso delimitar el origen de la guerra a caballo con estribos ${ }^{6}$.

El génesis de la invención, aparentemente simple, del estribo ha resultado ser una discusión mucho más compleja y profunda. Aunque existen registros de elementos similares al estribo que fueron utilizados en varias regiones de Asia, como la estepa central, o el subcontinente indio desde el primer siglo después de Cristo, casi siempre estaban hechos de materiales no metálicos o perecederos que dificultan la búsqueda de evidencia arqueológica en diferentes entierros de jinetes guerreros y que podrían dilucidar el dilema de su origen y presencia. De todas maneras, es posible afirmar que es durante la transición del siglo V al VI cuando los pueblos de las estepas de Asia Central y Europa del Este comenzaron a usar estribos metálicos (o con adornos metálicos) y transmitieron esta innovación tecnológica y táctica a los cuerpos militares de las grandes potencias de la época en Mesopotamia: el Imperio romano de Oriente y el Imperio sasánida ${ }^{7}$.

Algunos consideran que la primera referencia en fuentes escritas bizantinas sobre el estribo es en el Strategikon, una obra pseudo biográfica atribuida al emperador Mauricio (539-602 d.C.), pero escrita en realidad por un contemporáneo que tomó prestado el nombre del emperador. Independientemente de eso, este trabajo de finales del siglo VI no sólo dice que los estribos eran equipos estándar para los soldados

6 John Keagan, A history of warfare (Nueva York: Random House, 2011), 285-286.

7 Mary Aiken Littauer, Joost H Crouwel y Peter Raulwing, eds., Selected writings on chariots and other early vehicles, riding and harness, vol. 6. (Lieden: Brill, 2002), 440-449. 
de caballería, sino que también sugiere que ya habían estado en uso durante algún tiempo ${ }^{8}$. Un precursor de Mauricio, un escritor militar griego anónimo de principios del siglo VI, implicaba el uso de estribos por su descripción de tácticas de caballería pesada. Asimismo, se dice que los estribos se mencionan en fuentes chinas ya en 477 d. C ${ }^{9}$. Por otro lado, el arte romano y sasánida del siglo IV d. C. no muestra estribos en ninguno de los muchos ejemplos de arte ecuestre que sobrevivieron de este periodo. Sin embargo, algunos autores consideran que el estribo se remonta a una historia mucho más lejana de esta adopción tardía en el Mediterráneo ${ }^{10}$.

La teoría más aceptada es que el primer tipo de estribo era un simple lazo de cuero en un lado de la silla para ayudar al jinete a montar. Aparentemente fue inventado de esta forma por los escitas antes del año 100 a. C., como lo demuestran las pruebas arqueológicas, y el estribo gemelo y rígido fue inventado por los sármatas poco después del año 100 a. C. y los ayudó a derrocar al imperio escita. Es debido a la proximidad de estos pueblos que es difícil explicar el retraso de más de 500 años en la adopción de este dispositivo simple y útil, en forma de estribo rígido, en la cuenca del Mediterráneo ${ }^{11}$. Hacia el final de la Antigüedad tardía, el imperio encaró nuevos desafíos y el ejército se enfrentó a métodos de guerra desconocidos. El primero de ellos fue el mayor uso de la caballería contra los enemigos de Roma, y no cualquier caballería, sino jinetes fuertemente armados que montaban caballos blindados equipados con estribos. El ejército no tardó en apropiarse y aprender en profundidad estas técnicas de la caballería oriental. La adopción romana del estribo a finales del siglo VI alteró drásticamente el equilibrio de la efectividad y, por lo tanto, el éxito de las fuerzas, convirtiendo a la caballería en la fuerza ofensiva preeminente del ejército romano de Oriente en el campo de batalla ${ }^{12}$.

El estilo de equitación bizantino y sasánida consistía en sentarse bien delante de la montura, con las piernas dobladas y los pies apuntando hacia abajo para meter los talones del jinete detrás de las patas delanteras del caballo. La efectividad de este estilo de conducción se pudo comprobar y continuó en uso durante períodos posteriores, a pesar del advenimiento de un calzado mejor construido y la adopción del estribo dentro del imperio a fines del siglo VI (incluso este estilo sobrevive en el Cáucaso

$8 \quad$ Mauricio, emperador de Oriente, Strategikon, trad. Emilio Magaña Orúe, Julio Rodríguez González y José Ignacio de la Torre Rodríguez (Madrid: Subdirección General de Publicaciones y Patrimonio Cultural, Ministerio de Defensa, 2014), 358 p. Libro II, cap. 9, p. 112. George T. Dennis, ed. Maurice's Stratégikon: Handbook of Byzantine military strategy (Filadelfia: University of Pennsylvania Press, 2001), 30.

9 Albert E. Dien, "The Stirrup and Its Effect on Chinese Military History.” Ars Orientalis 16, (1986): 36, www.jstor.org/stable/4629341

10 L. Sprague De Camp, “Before Stirrups.” Isis 51, no. 2 (1960): 159, www.jstor.org/stable/226847

11 Ibid., 159.

12 Timothy Dawson, Byzantine Cavalryman, C. 900-1204. Vol. 139 (Oxford: Osprey Publishing, 2009), 9-10. 
hoy). En esta manera de conducir, los estribos sirven principalmente como un paso de montaje (de ahí la primera palabra griega medieval para ellos: skala o peldaño, escalera) y luego, colgando bastante flojo en el pie, como una ayuda de emergencia. Cuando el estribo se integró completamente en la práctica militar romana y el tiro con arco montado aumentó en importancia, el estilo de conducción de Asia Central con estribos más cortos que podía llevar más peso se hizo cada vez más común. Esta posición permitía disparar un arco más grande y poderoso, y principalmente facilitó el famoso "tiro parto" en el que el arquero disparaba una flecha directamente detrás de él, sin tener las manos en las bridas o riendas de su montura. Los mayores contactos entre Oriente y Occidente desde el cambio del milenio introdujeron en las estepas el estilo de caballería europeo más relajado con su asiento bajo y las piernas empujadas hacia adelante con estribos largos ${ }^{13}$.

\section{La caballería en el Imperio romano de Oriente}

Las guerras del emperador Justiniano (483-565 d. C.) en su proceso para la restauración del dominio imperial sobre los territorios que su contraparte occidental había perdido, representaron el primer gran ejemplo del cambio del modo de guerra romano que se había basado en las legiones de infantería desde la era republicana. Un cambio constante y progresivo hacia la posterior preponderancia de la caballería. Las hordas bárbaras conocidas como bucellarii se habían acercado e integrado lo suficiente para ser las tropas preferidas de los generales romanos, siendo esto una consecuencia del cambio de la naturaleza de las fuerzas imperiales que se había mantenido gradualmente durante un largo período, el típico jinete del período no era un legionario sino un arquero montado ${ }^{14}$.

Con este cambio en el estamento militar, Justiniano ya tenía en mente el objetivo a largo plazo de la reconquista de los territorios del Imperio romano de Occidente (el proceso denominado como Restauratio imperi), por eso, la expedición contra los vándalos en el año 533 d.C. fue enviada a lo grande. Se embarcó hacia el norte de África una fuerza de 10.000 soldados de infantería y 5.000 jinetes que contaba en sus filas con la participación de Procopio de Cesarea, el principal historiador del periodo, y el famoso general Belisario al mando ${ }^{15}$. Fueron despedidos de la capital por el emperador, la emperatriz Teodora y el patriarca, quienes levantaron oraciones por el éxito de la fuerza expedicionaria. Un triunfo que fue rápidamente evidente después de

\footnotetext{
13 Ibid., 24-26.

14 Averil Cameron, The Mediterranean world in late Antiquity: AD 395-700 (Londres: Routledge, 2015), 50. Conor Whately, Battles and Generals: Combat, Culture, and Didacticism in Procopius' Wars (Leiden: Brill, 2015), 2.

15 Averil Cameron, The Mediterranean world in late Antiquity, 108. Anthony Kaldellis and Ian Mladjov, The wars of Justinian (Indianápolis: Hackett Publishing, 2014), XIII.
} 
las primeras victorias de Belisario, aunque, si bien es cierto que la caballería romana, dispuesta como arqueros montados, tenía una mejor movilidad y, por lo tanto, tenía una ventaja sobre vándalos y posteriormente sobre los godos de la península itálica, pues ambas caballerías iban armadas con lanzas y espadas, su pequeño número constituía un problema importante, especialmente después de la retirada de Belisario hacia Constantinopla por Justiniano, y la ascensión de Totila en el año 541 d.C. como rey de los ostrogodos, quienes habían estado hostigando a las tropas romanas que combatían al enemigo mayor, el Imperio sasánida en la frontera oriental del imperio ${ }^{16}$.

Las tropas con mejor desempeño individual en este período para el ejército romano fueron indiscutiblemente los soldados de caballería. Procopio, en la introducción a sus Guerras, seleccionó al arquero montado como el epítome del guerrero moderno, quizás en parte porque éste era un claro contraste con el legionario romano tradicional equipado con escudo y espada ${ }^{17}$. Esta habilidad del arquero como jinete y el poder de su arco pesado pueden haber sido tomados de los hunos del siglo $\mathrm{V}$, pueblo de las estepas que continuó sirviendo como mercenarios del imperio durante todo el siglo VI, pero el entrenamiento en tiro con arco también fue recomendado para todos los reclutas ${ }^{18}$. De todas maneras, el ejército poseía una variedad de habilidades para sus también diversos enemigos y teatros de guerra: en los conflictos con los persas se aconsejaba a los romanos que confiaran en la superioridad de su poder de choque a través de la carga, lo que apunta a la existencia de caballería pesada de alta calidad equipada con lanzas ${ }^{19}$.

Algunos investigadores han intentado implementar los preceptos de manuales como el ya mencionado Strategikon y, a través de la arqueología experimental, han recreado los ejercicios de entrenamiento descritos allí. Estos intentos fueron útiles para revelar las debilidades en el diseño del estribo en forma de árbol y mostraron que el tipo de estribos grandes estaba destinado a tácticas de choque, no a largas distancias como lo sería su posterior contraparte medieval. Parte del problema que enfrenta un jinete moderno que intenta recrear la experiencia antigua es que ha aprendido a montar con estribos como habilidad principal, mientras que el romano estaba acostumbrado a montar sin ellos. Los estribos no aparecen en el registro arqueológico europeo antes del siglo VI d. C. al igual que la silla de montar con cuernos (similar a la que se usa hoy en día) apareciera durante el mismo periodo ${ }^{20}$. Es por esta razón

16 Averil Cameron, The Mediterranean world, 113.

17 Anthony Kaldellis and Ian Mladjov, The wars of Justinian, 3. Procopio de Cesarea, "Volumen I: Guerra Persa. Libros I-II", en Historia de las guerras. Obra completa, trad. Francisco Antonio García Romero (Madrid: Editorial Gredos, 2000) 9-16. Alexander Sarantis and Neil Christie, War and Warfare in Late Antiquity (2 vols.): Current Perspectives (Leiden: Brill, 2013), 27.

19 Averil Cameron, Bryan Ward-Perkins and Michael Whitby, eds., The Cambridge ancient history. Vol. 14 (Cambridge: Cambridge University Press, 2001), 310.

20 Peter Connolly y Carol Van Driel-Murray, "The Roman Cavalry Saddle”. Britannia, 22 (1991): 47-48. 
que el primer trabajo que los menciona, el Strategikon de Mauricio, no es una fuente completamente confiable y representa un problema para fechar la implementación del estribo en el ejército romano ${ }^{21}$.

\section{Las reformas, entrenamientos e innovaciones del emperador Hera- clio}

Avanzando cronológicamente y desviando un poco el foco de la caballería, es necesario detenerse en el asedio de Constantinopla en el verano de 626 d.C. Heraclio, quien como nuevo emperador terminaría de helenizar la mitad sobreviviente del imperio romano al - entre otras cosas - instaurar el griego como idioma oficial, tuvo que enfrentar en sus primeros años de reinado el segundo gran asedio de los veintitrés que la gran ciudad sufriría, cuando un masivo ejército combinado de persas, ávaros y otros aliados eslavos sitiaron la capital del Imperio de oriente. Antes de emprender la guerra en tierras persas, el emperador romano consideró que era probable un asedio de la ciudad, como había ocurrido el 5 de junio de 623 (aunque autores como José Soto Chica sitúan esta "sorpresa ávara" en el 619)"22 cuando, después de una breve conferencia en Tracia entre los representantes bizantinos y la coalición ávaro-persa, el khagan o líder de los ávaros, frustrado por una fallida solución diplomática para el conflicto, intentó secuestrar al emperador Heraclio y simultáneamente lanzó un asalto sobre Constantinopla a gran escala por mar y tierra ${ }^{23}$.

El emperador romano tenía claro que tanto la victoria en Mesopotamia como el asedio de su capital decidiría el destino de su imperio. Heraclio todavía estaba en el Oriente, en el teatro de campaña, siendo el primer emperador comandando al ejército romano desde la desastrosa batalla de Adrianópolis en el $378^{24}$ y la capital no estaba bajo su mando. En cambio, las defensas de la Constantinopla quedaron en manos de su capaz general Bonus y el patriarca Sergio ${ }^{25}$. Durante el asedio, los persas sasánidas, comandados por su rey Sharvaraz, no pudieron llevar refuerzos sustanciales a sus aliados eslavos por temor a que las fuerzas de Heraclio atacaran su tierra natal. Además, la batalla naval en el Bósforo fue un desastre para los atacantes, ya que la

21 Irfan Shahîd, Byzantium and the Arabs in the Sixth Century, vol. 1 (Washington: Dumbarton Oaks, 1995), 612.

22 José Soto Chica, "La gran Guerra Romano-Persa y los orígenes de la gran Bulgaria (585-630)", Byzantion nea hellás, 36 (2017): 275, http://dx.doi.org/10.4067/S0718-84712017000100262

23 Walter Emil Kaegi, Heraclius, emperor of Byzantium (Cambridge: Cambridge University Press, 2003): 118-120.

24 Para una detallada descripción de esta campaña, véase José Soto Chica, Bizancio y los Sasánidas. De la lucha por Oriente a las conquistas árabes (565-642) (Granada: Centro de Estudios Bizantinos, Neogriegos y Chipriotas, 2012), 413 pp., 107-204.

25 Gerrit J. Reinik, ed., The Reign of Heraclius (610-641): Crisis and Confrontation (Lovaina: Peeters, 2002), 157. 
flota bizantina infligió graves pérdidas a la flota ávara. Incluso sin los persas, la situación de los ávaros era desesperada debido a la infranqueabilidad de las murallas de Constantinopla y el asedio fue levantado. Providencialmente, la intuición de Heraclio y la confianza en sus subordinados fueron recompensados. Las defensas de la ciudad mostraron una fuerte resistencia tanto en tierra como en mar. Incluso con las defensas en su apogeo, los hombres que los defienden se verían en apuros para detener a los sitiadores que sumaban al menos 80,000 hombres quienes diezmados y desmoralizados, fueron consecuentemente vencidos. Los ávaros nunca más supondrían un desafío para Constantinopla.

Sin embargo, uno de los resultados más importantes del asedio fue la adquisición de la nueva tecnología que revolucionaría a los ejércitos bizantinos y luego al resto del mundo: el estribo ${ }^{26}$. A pesar de su inmensa importancia, este invento se incorporó a la caballería bizantina poco antes de la batalla de Nínive (diciembre de 627), aunque solo para las unidades de caballería pesada o catafractas —en griego: kataphraktoi - y en los tiempos de la batalla de Yarmouk (agosto de 636) la mayoría de las unidades de caballería bizantina se equiparían con este potente elemento de apoyo, aunque la contienda terminara en la primera derrota de un ejército bizantino a manos de un ejército árabe musulmán ${ }^{27}$. Oportunamente, los enemigos de Bizancio no contaban con esta poderosa ventaja táctica, lo cual en la victoria bizantina de Nínive representaría la superioridad de la máquina de guerra romana sobre el persa, pero no sería un factor determinante en la derrota de Yarmouk, en dónde el nuevo poder bélico en la región, representado por el califato Rashidun u ortodoxo de Abu Bakr y su general Khalid ibn al-Walid, significó un desafío desconocido para los ejércitos del Imperio romano de Oriente ${ }^{28}$.

Esta notable adopción táctica, especialmente en la forma de estribo de hierro, se logró bajo el emperador Heraclio. El estribo de hierro fue una tremenda reforma a la caballería porque aumentó la efectividad de la carga y elevó la calidad del tiro con arco a caballo, permitiendo a los bizantinos organizarse en ejércitos de caballería, o kavallarika themata ${ }^{29}$. Adrian Bivar argumenta que la renuencia sasánida de adoptar la tecnología nómada de la estepa en el tiro con arco de caballos fue perjudicial para su lucha con las catafractas bizantinas y una consecuencia de esto fue el resultado de Nínive. La negativa sasánida de reformar su caballería pesada o clibanarius se puede ver en Taq-i Bustan, donde en una estatua del emperador Cosroes II es retratado en su armadura pesada, pero el estribo está ausente ${ }^{30}$. La estatua nos lleva a suponer que

26 Shahîd, Byzantium and the Arabs, 612.

27 Theophanes, the Confessor, d. ca. 818, et al. The Chronicle of Theophanes Confessor: Byzantine and near Eastern History, A.D. 284-813 (Oxford: Clarendon Press, 1997), 112, 26; 171,13.

28 Albert Hourani, La historia de los árabes, trad. Aníbal Leal (Barcelona: Ediciones B, 2009), 48.

29 John Haldon, Byzantium at War AD 600-1453 (Londres: Routledge, 2004), 47.

30 A.D. H Bivar, "Cavalry Equipment and Tactics", 275. 
el clibanarius del ejército sasánida no debe tener este elemento, siendo la armadura del rey una representación que refleja su posición en el ejército a través de un equipo superior. Por medio de estos hechos, la caballería pesada de los Romaioi ("romanos" en el recién oficializado idioma griego) parecía haber estado en una mejor posición que los persas al adoptar la tecnología de las poderosas tribus de Asia Central. El tradicionalismo persa retrasó cualquier reforma para competir con los kataphraktoi más avanzados y, aunque los romanos parecían quedarse atrás en lo que respecta a la guerra a caballo desde la República tardía y durante el periodo de invasiones de los pueblos de las estepas, es en el gobierno del emperador Heraclio que el imperio pasó a la delantera con la ventaja táctica en el teatro de operaciones del Cercano Oriente. ${ }^{31}$

De manera convincente y siguiendo los argumentos de Mark-Anthony Karantabias, parece que el reclamo de Walter Kaegi sobre la derrota de los sasánidas puede ser contestado a través del entrenamiento de los kataphraktoi ${ }^{32}$. El largo proceso de su apropiación, capacitación y aplicación de la forma de estribo de nómadas esteparios, como los ávaros, hunos y quizás los gökturk (aliados de Bizancio) fue un proceso importante, y esto no está incluido en el acápite del Strategikon que se refiere a los enemigos del Imperio bizantino ${ }^{33}$. Ya sea por las tácticas establecidas en la sección anterior o la adopción de su nuevo equipo como el arco compuesto y el estribo de hierro, la caballería pesada bizantina estuvo cada vez más cerca de imitar al arquero a caballo de los nómadas esteparios, pero con el plus de la armadura pesada tradicional de la caballería imperial. El largo proceso culminó bajo la supervisión directa del emperador Heraclio cuando movilizó y entrenó a fondo a su ejército en la ciudad de Cesarea para adoptar efectivamente estas "nuevas" tácticas en un ejercicio militar sin precedentes en la historia del Imperio romano de Oriente ${ }^{34}$.

Los procedimientos en Cesarea fueron revolucionarios para la caballería de catafractas, el ejército bizantino y para la historia militar misma por dos razones: en primera instancia, es un inusual ejemplo de una ocasión en el mundo premoderno en la que se estableció un elemento táctico en un ejército de una manera institucionalizada y rápida. En segundo lugar, fue un punto de quiebre en donde los bizantinos, quienes luego de estar entrenando intensivamente durante al menos medio año, emergieron como un ejército poderoso y con la ventaja táctica. Poseía la infantería bizantina tradicional que era superior a la de los sasánidas y los nuevos kataphraktoi entrenados y

$31 \quad$ Mark-Anthony Karantabias, "The Crucial Development of Heavy Cavalry under Herakleios and His Usage of Steppe Nomad Tactics, ” Hirundo: The McGill Journal of Classical Studies 4 (2005): 30.

32 Kaegi, Heraclius, emperor of Byzantium, 308-309.

33 Sarantis y Christie, War and Warfare, 63.

34 Para la descripción por parte de Jorge de Pisidia, un testigo presencial de los ejercicios, véase Espejo Jáimez, G. Estudio, traducción, anotaciones y comentarios de los panegíricos épicos, obra poética de Jorge de Pisidia, Trabajo de Investigación de DEA, Universidad de Granada 2006. Soto Chica, José. "Bizantinos, sasánidas y musulmanes. El fin del mundo antiguo y el inicio de la Edad Media en Oriente 565-642” (Tesis Doctoral en Historia Medieval, Universidad de Granada, 2012), 121. 
equipados con las tácticas nómadas de la estepa, las cuales resultarían fatales para los persas. Por lo tanto, parece que Heraclio podría haber usado el Strategikon, pero no a través de los medios que afirmó, sino más bien por la forma en que los nómadas de la estepa luchaban, como se describe en el undécimo libro del Strategikon ${ }^{35}$.

\section{Conclusión}

En resumen, la apropiación del estribo por el Imperio romano de Oriente y su masificación gracias al emperador Heraclio, sería un elemento táctico que inclinaría hacia sus dominios el equilibrio de poder en la frontera entre el Imperio romano de Oriente y el imperio persa sasánida. Fue bajo el mando del emperador Heraclio y teniendo como soporte teórico el manual atribuido al emperador Mauricio, que la caballería romana prevalecería tanto en la estructura militar del imperio como en la cambiante concepción de la guerra misma durante este período, influyendo en otros pueblos que usarían esta invención contra los bizantinos mismos. Dado que no fue de los ejércitos sasánidas que los árabes aprendieron el uso de estribos, es justo concluir que fue de los ejércitos bizantinos de Heraclio, que a su vez lo aprendieron a través de su contacto con los ávaros. A lo largo del período que se ha analizado aquí, los principales cambios e innovaciones en la guerra a caballo las proveyeron las sociedades nómadas que evolucionaron en Asia Central. Con estos, tanto Bizancio como Persia tuvieron encuentros separados y, a menudo, mortificantes ${ }^{36}$.

Estos contactos - evidentemente no siempre pacíficos - en el Cercano Oriente entre diversas ciudades e imperios y sus respectivas concepciones para ver la guerra generaron cambios en el desarrollo de esta, siempre en busca de la superioridad militar y, por ende, superioridad política. El contacto del ejército del Imperio romano de oriente con la tecnología del estribo y su posterior apropiación y uso, sería la puerta de entrada a la configuración de la guerra a caballo como componente central de los conflictos bélicos en la Edad Media y, subsecuentemente, de las relaciones políticas y económicas. El caballero pesado, con una silla de montar fija y estribos, destinado a ser el elemento de choque durante el combate, reconocido como un símbolo por antonomasia del sistema feudal y la tradición literaria caballeresca, se convertiría en el elemento más común en los campos de batalla medievales hasta la llegada de otros cambios tácticos y tecnológicos como el desarrollo y proliferación de las armas de fuego, un proceso que tardaría casi un milenio desde que el ejército del emperador Heraclio decidió proveer a su caballería con los estribos que le habían visto a los ávaros y otros pueblos nómadas en el campo de batalla.

35 Karantabias, “The Crucial Development”, 39; Dennis, ed., Maurice's Stratégikon, 116.

36 Bivar, "Cavalry Equipment and Tactics", 290. 
Pero todo este devenir de acontecimientos y combates a caballo en polvorientos parajes entre nómadas e imperios no es un problema histórico ajeno a nuestro contexto. Es evidente que la violencia sea ejercida, proyectada o modificada, es una característica omnipresente en el contexto histórico y geográfico que se ha analizado en este artículo. Sin embargo, en nuestro devenir histórico y, específicamente, en uno de nuestros periodos históricos nacionales más estudiados, existieron jinetes que combatieron, cruzaron ríos, valles y cordilleras con o sin estribos en sus monturas. La campaña libertadora, de la futura Colombia, de 1819, fresca en la memoria colectiva por su reciente bicentenario, es un episodio de nuestra historia que, a través de sus documentos, representaciones iconográficas y construcciones historiográficas y de memoria colectiva, nos representa dos tipos de héroes: los criollos, ilustrados y bien pertrechados, con sus monturas con elaboradas bridas y como no, estribos. Y los otros héroes, encasillados, voluntaria o involuntariamente, como una alegoría del pueblo llano que luchó por cambiar sus condiciones de vida montando a pelo, sin silla y sin estribos, inmortalizados en bronce en su carga inmortal en el Pantano de Vargas.

Esta diferencia, aparte de las obviedades del poder adquisitivo y la jerarquía militar entre la oficialidad y los soldados o lanceros, nos demuestra que los cambios en las ventajas tácticas en una guerra no son necesariamente uniformes, ni tienen un carácter teleológico. Es con este problema en mente que los estudios sobre historia e historiografía militar deben sustentarse. Nuestra historia bélica, por un sinnúmero de características, limitaciones y cualidades, tan alejada y presente al mismo tiempo, debe analizarse desde una perspectiva abierta y dispuesta a acercarse a nuevos enfoques y desafíos.

\section{Bibliografía y fuentes primarias}

Bivar, A. D. H. "Cavalry Equipment and Tactics on the Euphrates Frontier." Dumbarton Oaks Papers 26 (1972): 271-291, www.jstor.org/stable/1291323

Cameron, Averil, Bryan Ward-Perkins y Michael Whitby, eds. The Cambridge ancient history. Vol. 14. Cambridge: Cambridge University Press, 2001.

Cameron, Averil. The Mediterranean world in late Antiquity: AD 395-700. Routledge, 2015.

Cesarea, Procopio de. Historia de las guerras. Obra completa. Trad. Francisco Antonio García Romero. Madrid: Editorial Gredos, 2000.

Connolly, Peter y Carol Van Driel-Murray. "The Roman Cavalry Saddle." Britannia, 22 (1991): 33-50, www.jstor.org/stable/526629 
Dawson, Timothy. Byzantine Cavalryman, C. 900-1204. Vol. 139. Osprey Publishing, 2009.

De Camp, L. Sprague. “Before Stirrups.” 51, n. ${ }^{\circ} 2$ (1960): 159-160, www.jstor.org/ stable/226847

Dennis, George T., ed. Maurice's Stratégikon: Handbook of Byzantine military strategy. Filadelfia: University of Pennsylvania Press, 2001.

Dien, Albert E. "The Stirrup and Its Effect on Chinese Military History." Ars Orientalis, 16 (1986): 33-56, www.jstor.org/stable/4629341

Espejo Jáimez, Gonzalo. Estudio, traducción, anotaciones y comentarios de los panegíricos épicos, obra poética de Jorge de Pisidia. Trabajo de investigación de DEA Universidad de Granada, 2006.

Haldon, John. Byzantium at War AD 600-1453. Londres: Routledge, 2004.

Hourani, Albert. La historia de los árabes, Trad., Aníbal Leal. Barcelona: Ediciones B, 2009.

Jeffreys, Elizabeth, John F. Haldon y Robin Cormack, eds. The Oxford Handbook of Byzantine Studies. Oxford: Oxford Handbooks, 2008.

Kaegi, Walter Emil. Heraclius, emperor of Byzantium. Cambridge: Cambridge University Press, 2003.

Kaldellis, Anthony e Ian Mladjov. The wars of Justinian. Indianápolis: Hackett Publishing, 2014.

Karantabias, Mark-Anthony. "The Crucial Development of Heavy Cavalry under Herakleios and His Usage of Steppe Nomad Tactics." Hirundo: The McGill Journal of Classical Studies, 4 (2005): 28-41.

Keegan, John. A history of warfare. Nueva York: Random House, 2011.

Littauer, Mary Aiken, Joost H. Crouwel y Peter Raulwing, eds. Selected writings on chariots and other early vehicles, riding and harness, vol. 6. Leiden: Brill, 2002. 
Mauricio, emperador de Oriente. Strategikon. trad. Emilio Magaña Orúe, Julio Rodríguez González y José Ignacio de la Torre Rodríguez. Madrid: Subdirección General de Publicaciones y Patrimonio Cultural, Ministerio de Defensa, 2014.

McAllister, S. E. The sword and shield of god: Byzantine strategy and tactics under heraclius during the last persian war and first arab war. ProQuest Dissertations \& Theses Global: The Humanities and Social Sciences Collection (2007), https://search.proquest.com/docview/304740436?accountid=15607

Reinink, Gerrit J., ed. The Reign of Heraclius (610-641): Crisis and Confrontation. Lovaina: Peeters, 2002.

Sarantis, Alexander y Neil Christie. War and Warfare in Late Antiquity (2 vols.): Current Perspectives. Leiden: Brill, 2013.

Shahîd, Irfan. Byzantium and the Arabs in the Sixth Century. Vol. 1. Washington: Dumbarton Oaks, 1995.

Soto Chica, José. "Bizantinos, sasánidas y musulmanes. El fin del mundo antiguo y el inicio de la Edad Media en Oriente 565-642", tesis doctoral en Historia Medieval, Universidad de Granada, 2012.

---. Bizancio y los Sasánidas. De la lucha por Oriente a las conquistas árabes (565642). Granada: Centro de Estudios Bizantinos, Neogriegos y Chipriotas, 2012.

---. 'La gran Guerra Romano-Persa y los orígenes de la gran Bulgaria (585-630)." Byzantion nea hellás, 36 (2017): 262-281, http://dx.doi.org/10.4067/S071884712017000100262

Theophanes, the Confessor, d. ca. 818, et al. The Chronicle of Theophanes Confessor: Byzantine and near Eastern History, A.D. 284-813. Oxford: Clarendon Press, 1997.

Uribe Rueda, Álvaro. Bizancio, el dique iluminado: la concepción mística del universalismo, sus raíces judias y helénicas y su herencia cristiana. Bogotá: Instituto Caro y Cuervo, 1997.

Whately, Conor. Battles and Generals: Combat, Culture, and Didacticism in Procopius' Wars. Leiden: Brill, 2015. 
Wolf, Hieronymus. Corpus Historiae Byzantinae, 34 vol. Fráncfort, 1568. Disponible en: http://mdz-nbn-resolving.de/urn:nbn:de:bvb:12-bsb10140060-5 